\title{
VARIABILIDADE DAS CARACTERÍSTICAS QUÍMICAS E MINERALÓGICAS DE SOLOS DA REGIÃO METROPOLITANA DE CURITIBA (PR) ${ }^{1}$ \\ VARIABILITY IN THE CHEMICAL AND MINERALOGICAL CHARACTERISTICS IN SOILS FROM CURITIBA METROPOLITAN AREA (PR)
}

\author{
Leila Chamma BARBAR ${ }^{2}$ \\ Vander de Freitas $\mathrm{MELO}^{3}$
}

\begin{abstract}
RESUMO
O propósito deste trabalho foi estudar as variações nos teores totais de elementos e atributos mineralógicos do solo em curtas distâncias horizontais de amostras (repetições) dos horizontes A e B em cinco áreas na Região Metropolitana de Curitiba. A fração silte+argila foi estudada por difratometria de raios-X, análise termodiferencial, análise termogravimétrica e análises químicas. Os teores totais de $\mathrm{Fe}, \mathrm{Al}, \mathrm{Mg}, \mathrm{Zn}, \mathrm{Mn}, \mathrm{Cu}, \mathrm{Ni}, \mathrm{Pb}$ e $\mathrm{Cr}$ foram determinados após a digestão ácida das amostras $\left(\mathrm{HF}, \mathrm{HNO}_{3}, \mathrm{H}_{2} \mathrm{SO}_{4}\right.$ e $\mathrm{HClO}_{4}$ ). Os teores de $\mathrm{Fe}$ e Al foram determinados após extração das amostras com oxalato de amônio (OA), ditionito-citrato-bicarbonato (DCB) e solução de $\mathrm{NaOH} 0,5 \mathrm{~mol} \mathrm{~L}^{-1}$. Mesmo sendo mais estáveis que os teores trocáveis de nutrientes, verificou-se variações nos atributos mineralógicos entre as repetições coletadas em pontos próximos em uma mesma área, principalmente, para solos originados de rochas sedimentares. Os valores dos coeficientes de variação (CV) foram inversamente proporcionais à estabilidade da característica analisada: teores totais de elementos e teores de minerais de alta cristalinidade apresentaram menores CV; comportamento oposto foi verificado para os teores de óxidos de $\mathrm{Fe}$ e Al de baixa cristalinidade. As características cristalográficas da caulinita e gibbsita foram homogêneas.
\end{abstract}

Palavras-chave: caulinita; óxidos de $\mathrm{Fe}$ e Al; minerais de baixa cristalinidade; cristalografia.

\begin{abstract}
Aiming to evaluate the variations in the total elements contents and mineralogical characteristics in a short horizontal soil distance, four composite samples (repetitions) were taken from A and B horizons in five areas in the Curitiba Metropolitan Region. The silt+clay fraction was investigated by $\mathrm{X}$-ray diffraction, differential thermal analysis, thermogravimetry and chemical analysis. Total $\mathrm{Si}, \mathrm{Al}$ and $\mathrm{Fe}$ contents were determined after clay sample digestion by concentrated acids $\left(\mathrm{HF}, \mathrm{HNO}_{3}\right.$, $\mathrm{H}_{2} \mathrm{SO}_{4}$ e $\mathrm{HClO}_{4}$ ). The $\mathrm{Fe}$ and $\mathrm{Al}$ contents were determined from ammonium oxalate (AO), citrate-bicarbonate-dithionite (CBD) and $\mathrm{NaOH} 0,5 \mathrm{~mol} \mathrm{~L}^{-1}$ extracts. It was observed variations in the mineralogical characteristics between replications in the same area, mainly for soils originated from limestone and claystone rocks. The variation coefficient (VC) was inversely related to stability of the characteristics analyzed: total element contents and crystalline mineral contents had lower VC values; opposite behavior was observed to $\mathrm{Fe}$ and $\mathrm{Al}$ amorphous oxide contents. The crystallography characteristics of the kaolinite and gibbisite were relatively homogeneous.

Key-words: kaolinite; Fe and Al oxides; amorphous minerals; crystallography.
\end{abstract}

${ }^{1}$ Parte do trabalho de dissertação de mestrado do primeiro autor.

${ }^{2}$ Mestre em Ciência do Solo, Instituto de Criminalística do Estado do Paraná, Rua Visconde de Guarapuava, 2652, CEP 80010-100, Curitiba (PR). Icbarbar@hotmail.com.

${ }^{3}$ Departamento de Solos e Engenharia Agrícola, Universidade Federal do Paraná - UFPR. Rua dos Funcionários, 1540, Juvevê, CEP 80035050, Curitiba (PR). Bolsista CNPq. vanderfm@ufpr.br. Autor para correspondência. 


\section{INTRODUÇÃO}

À medida que os solos evoluem, sua composição mineral começa a depender mais do ambiente de intemperização do que da composição do seu material de origem (WHITE e BRANTLEY, 1995). Neste contexto, a composição mineral das frações mais finas pode ser usada para estabelecer o estágio de intemperização de um solo, em função da espécie mineral na argila e silte (ESSINGTON, 2004). Minerais primários nas frações areia e silte de solos, principalmente silicatos (exceto quartzo e muscovita), podem intemperizar rapidamente em condições favoráveis, isto é, quando há elevada disponibilidade de água (GOLDICH, 1938; ANAND e GILKES, 1984) e se transformarem em minerais secundários (fração argila).

As alterações, transformações e neoformações de minerais que ocorrem no ambiente do solo no decurso da intemperização são condicionadas por numerosos fatores físicos, químicos e biológicos. Os principais fatores que determinam a intemperização dos minerais são (KÄMPF e CURI, 2003): (1) a estabilidade estrutural intrínseca do mineral; (2) $\circ \mathrm{pH}$ (concentração de prótons) da solução; (3) a presença de ligantes complexantes (ácidos orgânicos, ânions inorgânicos); (4) a área superficial específica do mineral; e (5) a eficiência da remoção dos produtos solúveis da intemperização (por precipitação, lixiviação, etc.).

Portanto, as variações nas características dos solos são incrementadas por mudanças locais de umidade, absorção, lixiviação, atividade biológica, $\mathrm{pH}$, etc. Como resultado, o solo pode ser bastante heterogêneo, o que dificulta a tomada de amostra capaz de representar suas características. Um dos aspectos mais importantes da amostra é sua representatividade: quanto mais homogêneo for o solo, maior será a facilidade de se obter uma amostra representativa (SPIECEL, 1978; VIEIRA, 1980; MEYER, 1983). Existem vários estudos mostrando a grande variação nos teores de nutrientes trocáveis e disponíveis às plantas em uma curta distância horizontal na unidade pedológica (KITCHEN et al., 1990; WOLLENHAUPT, 1994). Um dos métodos de amostragem usados para representar melhor uma determinada área é a tomada de amostras compostas de solos, ou seja, mistura de várias amostras simples coletadas em vários pontos na área (CATANS et al., 1954; BARRETO et al., 1974).

Em contraste com os diversos trabalhos na área de fertilidade do solo, são poucos os estudos de variações de características mais estáveis no solo, como a mineralogia das frações areia, silte e argila, para uma mesma área, em função do local de amostragem (variação horizontal). Segundo SCHAEFER (2001) a atividade de algumas espécies da mesofauna tropical (minhocas, por exemplo) afeta a estrutura do solo pela ingestão seletiva de partículas minerais e orgânicas e eliminação destas como coprólitos ou pelotas fecais, misturando as partículas do solo e homogeneizando as características mineralógicas do solo a curtas distâncias para um mesmo horizonte. Espera-se que esse efeito seja ainda mais pronunciado em solos mais intemperizados, como os Latossolos. A pedoturbação promove redistribuição e acumulação dos minerais, através dos fluxos percolantes, dos processos de expansão e contração promovidos pelos ciclos de umedecimento e secamento do solo, bem como de ações biológicas (bioturbação). Por outro lado, o estudo desenvolvido por TOLEDO (2006) mostrou que os teores e características dos minerais da fração argila são variáveis em função do tamanho dos agregados do horizonte $B$ de Latossolos (variações a curtas distâncias horizontais e verticais em função da posição do agregado na matriz do solo). $O$ autor concluiu que, mesmo a intensa e contínua pedogênese dos Latossolos, não foram suficientes para homogeneizar as características mineralógicas das diferentes classes de agregados, principalmente para 0 horizonte $\mathrm{Bw}$ do Latossolo Bruno. A comprovação dessa hipótese implicaria em prever que as raízes explorariam microambientes distintos em relação à composição mineralógica do solo durante o crescimento das plantas.

Dessa forma, o objetivo desse trabalho foi estudar as variações em atributos mais estáveis do solo (teores totais de elementos e mineralogia das frações mais finas do solo) em curtas distâncias horizontais dos horizontes $A$ e $B$ de Cambissolos (amostragem composta por quadrante) em cinco áreas na Região Metropolitana de Curitiba.

\section{METODOLOGIA}

\section{Seleção das áreas e amostragem do solo}

O estudo foi conduzido no Estado do Paraná, em três bairros da cidade de Curitiba Cajuru, Cidade Industrial (CIC) e Sítio Cercado e em dois municípios da Região Metropolitana de Curitiba (RMC): Colombo (Bairro Alto Maracanã) e São José dos Pinhais (Bairro Colônia Rio Grande) (Tabela 1). As coordenadas UTM dos pontos variaram de 667667 a $682113 \mathrm{~m}$ e de 7171770 a $7192576 \mathrm{~m}$ fuso 22 sul, e a altitude de 913 a $923 \mathrm{~m}$. Todos os solos foram classificados como Cambissolo Háplico Tb Distrófico típico (EMBRAPA, 1999), sendo formados a partir do intemperismo do argilito da Formação Guabirotuba, calcário e granito (Tabela 1).

Em cada bairro (total de 5 sítios) selecionouse um terreno livre de construções e coletaram-se 4 amostras compostas (quadrantes ou repetições) (Figura 1). Antes da mistura para a obtenção da amostra composta por quadrante, as amostras simples foram pesadas, tomando-se sempre a mesma quantidade de amostra $(400 \mathrm{~g})$. Ao final, a massa de cada amostra composta era de aproximadamente $1200 \mathrm{~g}$. Após a coleta das amostras do horizonte $A$, os mesmos procedimentos foram adotados para a amostragem do horizonte $B$ (coleta com trado, a diferentes profundidades, em função da espessura do horizonte B - Tabela 1). Ao final, obtiveram-se 40 amostras compostas (5 locais (sítios) de coleta $\times 2$ horizontes $\times 4$ repetições) (Tabela 1) para realização das análises. 
TABELA 1 - Características dos locais de amostragem

\begin{tabular}{|c|c|c|c|c|c|c|c|c|}
\hline Amostra & Sítio & Repetição & Horizonte & Notação & $\begin{array}{l}\text { Profundidade } \\
\text { (cm) }\end{array}$ & Bairros $^{(1)}$ & $\begin{array}{c}\text { Silte+argila } \\
\mathrm{g} \mathrm{kg}^{-1}\end{array}$ & $\begin{array}{l}\text { Material } \\
\text { origem } \\
(2)\end{array}$ \\
\hline 1 & 1 & 1 & $A$ & $1-1 A$ & $0-25$ & Sítio Cercado & 788 & Argilito \\
\hline 2 & 1 & 2 & $A$ & $1-2 A$ & $0-25$ & Sítio Cercado & 803 & Argilito \\
\hline 3 & 1 & 3 & $A$ & $1-3 A$ & $0-25$ & Sítio Cercado & 719 & Argilito \\
\hline 4 & 1 & 4 & $A$ & $1-4 A$ & $0-25$ & Sítio Cercado & 646 & Argilito \\
\hline 5 & 1 & 1 & B & $1-1 B$ & $50-80$ & Sítio Cercado & 651 & Argilito \\
\hline 6 & 1 & 2 & B & $1-2 B$ & $50-80$ & Sítio Cercado & 461 & Argilito \\
\hline 7 & 1 & 3 & $\mathrm{~B}$ & $1-3 B$ & $50-80$ & Sítio Cercado & 553 & Argilito \\
\hline 8 & 1 & 4 & B & $1-4 B$ & $50-80$ & Sítio Cercado & 577 & Argilito \\
\hline 9 & 2 & 1 & $A$ & $2-1 A$ & $0-5$ & Cajuru & 801 & Argilito \\
\hline 10 & 2 & 2 & $A$ & $2-2 A$ & $0-5$ & Cajuru & 799 & Argilito \\
\hline 11 & 2 & 3 & $A$ & $2-3 A$ & $0-5$ & Cajuru & 821 & Argilito \\
\hline 12 & 2 & 4 & $A$ & $2-4 A$ & $0-5$ & Cajuru & 831 & Argilito \\
\hline 13 & 2 & 1 & B & $2-1 B$ & $55-70$ & Cajuru & 785 & Argilito \\
\hline 14 & 2 & 2 & B & $2-2 B$ & $55-70$ & Cajuru & 826 & Argilito \\
\hline 15 & 2 & 3 & B & $2-3 B$ & $55-70$ & Cajuru & 819 & Argilito \\
\hline 16 & 2 & 4 & $B$ & $2-4 B$ & $55-70$ & Cajuru & 808 & Argilito \\
\hline 17 & 3 & 1 & $A$ & $3-1 A$ & $0-40$ & $\mathrm{CIC}$ & 853 & Argilito \\
\hline 18 & 3 & 2 & $A$ & $3-2 A$ & $0-40$ & $\mathrm{CIC}$ & 816 & Argilito \\
\hline 19 & 3 & 3 & $A$ & $3-3 A$ & $0-40$ & $\mathrm{CIC}$ & 862 & Argilito \\
\hline 20 & 3 & 4 & $A$ & $3-4 A$ & $0-40$ & $\mathrm{CIC}$ & 874 & Argilito \\
\hline 21 & 3 & 1 & B & $3-1 B$ & $70-95$ & $\mathrm{CIC}$ & 840 & Argilito \\
\hline 22 & 3 & 2 & B & $3-2 B$ & $70-95$ & $\mathrm{CIC}$ & 841 & Argilito \\
\hline 23 & 3 & 3 & $\mathrm{~B}$ & $3-3 B$ & $70-95$ & $\mathrm{CIC}$ & 843 & Argilito \\
\hline 24 & 3 & 4 & B & $3-4 B$ & $70-95$ & $\mathrm{CIC}$ & 804 & Argilito \\
\hline 25 & 4 & 1 & $A$ & $4-1 \mathrm{~A}$ & $0-15$ & Alto Maracanã & 647 & Calcário \\
\hline 26 & 4 & 2 & $A$ & $4-2 A$ & $0-15$ & Alto Maracanã & 635 & Calcário \\
\hline 27 & 4 & 3 & $A$ & $4-3 A$ & $0-15$ & Alto Maracanã & 623 & Calcário \\
\hline 28 & 4 & 4 & $A$ & $4-4 \mathrm{~A}$ & $0-15$ & Alto Maracanã & 654 & Calcário \\
\hline 29 & 4 & 1 & $B$ & $4-1 B$ & $90-105$ & Alto Maracanã & 625 & Calcário \\
\hline 30 & 4 & 2 & $B$ & $4-2 B$ & $90-105$ & Alto Maracanã & 661 & Calcário \\
\hline 31 & 4 & 3 & B & $4-3 B$ & $90-105$ & Alto Maracanã & 652 & Calcário \\
\hline 32 & 4 & 4 & B & $4-4 B$ & $90-105$ & Alto Maracanã & 640 & Calcário \\
\hline 33 & 5 & 1 & $A$ & $5-1 A$ & $0-25$ & Rio Grande & 676 & Granito \\
\hline 34 & 5 & 2 & $A$ & $5-2 A$ & $0-25$ & Rio Grande & 682 & Granito \\
\hline 35 & 5 & 3 & $A$ & $5-3 A$ & $0-25$ & Rio Grande & 674 & Granito \\
\hline 36 & 5 & 4 & $A$ & $5-4 A$ & $0-25$ & Rio Grande & 631 & Granito \\
\hline 37 & 5 & 1 & $\mathrm{~B}$ & $5-1 B$ & $50-70$ & Rio Grande & 706 & Granito \\
\hline 38 & 5 & 2 & $B$ & $5-2 B$ & $50-70$ & Rio Grande & 750 & Granito \\
\hline 39 & 5 & 3 & $\mathrm{~B}$ & $5-3 B$ & $50-70$ & Rio Grande & 761 & Granito \\
\hline 40 & 5 & 4 & $\mathrm{~B}$ & $5-4 B$ & $50-70$ & Rio Grande & 676 & Granito \\
\hline
\end{tabular}

(1) Sítio Cercado, Cajuru e CIC (Cidade Industrial) - bairros de Curitiba; Alto Maracanã - bairro de Colombo; Colônia Rio Grande - bairro de São José dos Pinhais. ${ }^{(2)}$ Argilito da Formação Guabirotuba. 


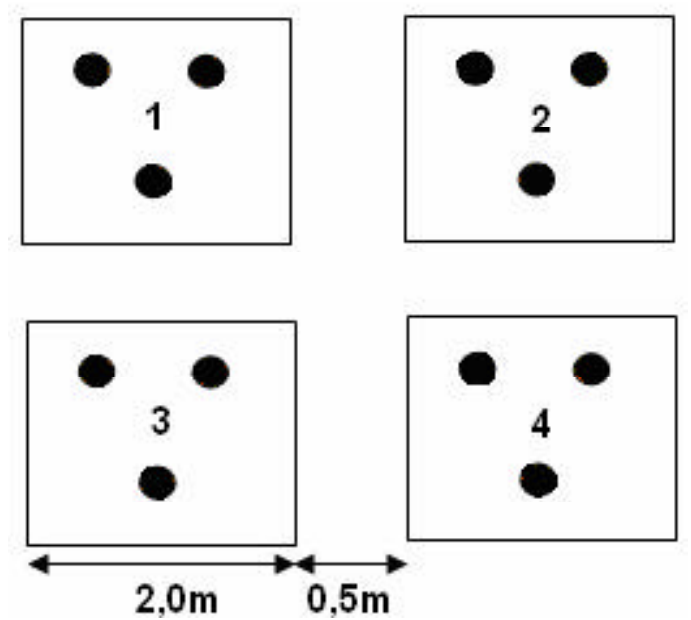

FIGURA 1 - Representação esquemática dos locais de amostragem dos horizontes A e B dos solos na área selecionada (sítio), evidenciando a coleta de 3 amostras simples por horizonte em cada quadrante (repetição). 1, 2, 3 e 4 - quadrantes ou repetições. Área útil por quadrante - 4 m². Bordadura- 0,5 m.

\section{Preparação das amostras de solo}

Após dispersão mecânica das amostras de solo (TFSA), a fração areia foi retida em peneira de $0,05 \mathrm{~mm}$ e a fração mais fina (silte mais argila) foi tratada com peróxido de hidrogênio $\left(\mathrm{H}_{2} \mathrm{O}_{2}\right)$ a $30 \%$ (v/v) em banho-maria a $60{ }^{\circ} \mathrm{C}$ para remoção da matéria orgânica (JACKSON, 1979). A percentagem da fração argila mais silte no solo foi determinada após secagem e pesagem da amostra livre da fração areia e matéria orgânica (Tabela 1).

A escolha da fração silte mais argila para realização das análises químicas e mineralógicas foi devido: 1) inclusão da fração argila: pela presença de minerais secundários, de maior ou menor cristalinidade, é a fração que mais influencia nas propriedades físico-químicas do solo e que melhor responde às extrações químicas. 2) inclusão da fração silte: devido ao seu reduzido tamanho $(0,05$ a $0,002 \mathrm{~mm})$, a fração silte não dificultou a homogeneização da amostra; devido a maior facilidade de intemperismo dos minerais primários fontes de nutrientes da fração silte em relação à fração areia (maior superfície específica), essa fração torna-se importante na dinâmica de liberação de nutrientes para as plantas (reserva mineral estimada pelos teores totais dos elementos).

\section{Análises químicas e mineralógicas na fração silte mais argila}

\section{Identificação mineralógica por difratometria de raios-X (DRX)}

A fração silte mais argila foi moída e montada em placas de Koch (amostra em pó), para identificação dos minerais por DRX. Os difratogramas foram obtidos em goniômetro vertical (PHILIPS, modelo PW 1050/70), com velocidade de $1{ }^{\circ} 2 \theta \mathrm{min}^{-1}$ e varredura de 4 a $60{ }^{\circ} 2 \Theta$.O difratômetro, equipado com filtro de níquel e utilizando radiação CuK $\alpha$, foi operado a $20 \mathrm{~mA}$ e $40 \mathrm{kV}$.

\section{Determinação dos teores totais de elementos \\ O método empregado na determinação dos teores totais de elementos na fração silte mais}

argila consistiu na digestão da amostra com HF, $\mathrm{HNO}_{3}, \mathrm{HClO}_{4}$ e $\mathrm{H}_{2} \mathrm{SO}_{4}$ concentrados (LIM e JACKSON, 1986). Foi colocado cerca de $0,1 \mathrm{~g}$ de amostra num bequer de teflon com capacidade de $50 \mathrm{~mL}$. A amostra foi umedecida com 5 gotas de $\mathrm{H}_{2} \mathrm{SO}_{4}$ e, em seguida, acrescentaram-se $5 \mathrm{~mL}$ de $\mathrm{HF}$ e $1 \mathrm{~mL}$ de $\mathrm{HNO}_{3}$. Os béqueres foram distribuídos em banho de areia a $230{ }^{\circ} \mathrm{C}$, onde permaneceram por, aproximadamente, $15 \mathrm{~min}$. Uma nova porção de $5 \mathrm{~mL}$ de HF foi adicionada e os béqueres, parcialmente tampados (cerca de 9/ 10), foram deixados no banho de areia por mais 30 a $40 \mathrm{~min}$, até completa evaporação (formação de resíduo seco). Para garantir a dissolução dos minerais mais resistentes, adicionaram-se mais $5 \mathrm{~mL}$ de HF, permitindo a formação de novo resíduo seco. Ao resíduo, foram adicionados $2 \mathrm{~mL}$ de água e 4 gotas de $\mathrm{HNO}_{3}$, deixando-se evaporar em ambiente aberto. Ao final, para dissolução do resíduo, $5 \mathrm{~mL}$ de $\mathrm{HCl} 6 \mathrm{~mol} \mathrm{~L}^{-1}$ e $5 \mathrm{~mL}$ de água foram adicionados, deixando os béqueres em banho de areia até início de fervura. Os teores de $\mathrm{Fe}, \mathrm{Al}, \mathrm{Mg}, \mathrm{Cr}, \mathrm{Mn}, \mathrm{Zn}$, Cu, Ni e Pb foram dosados por espectroscopia ótica por emissão atômica com plasma indutivamente acoplado (ICP-AES).

\section{Dissoluções seqüenciais}

Para definição da seqüência das análises na fração silte mais argila, utilizou-se o método proposto por MELO et al. (2002), conforme descrito nos itens seguintes. Os procedimentos comuns mais importantes nas análises seqüênciais foram:

- após centrifugação, procedeu-se a leitura de $\mathrm{Fe}$ e Al nos extratos obtidos de cada extração, conforme descrito anteriormente (ICP-AES);

- para remoção do excesso de sais (evitar interferência na massa seca da amostra após extrações), ao final das extrações o resíduo de cada amostra foi lavado com solução de carbonato de amônio $0,5 \mathrm{~mol} \mathrm{~L}^{-1}$ e com água deionizada. Em seguida os tubos de centrifuga foram colocados para secar em estufa a $60^{\circ} \mathrm{C}$ durante $24 \mathrm{~h}$, para determinação da massa final da amostra. 


\section{Extração de óxidos de ferro e alumínio de baixa cristalinidade}

A extração de alumínio e óxidos de ferro amorfos foi realizada em amostras de silte mais argila, utilizando-se apenas uma extração com oxalato de amônio $0,2 \mathrm{~mol} \mathrm{~L}^{-1}, \mathrm{pH} 3,0$, na ausência de luz (OA) (McKEAGUE, 1978). Foram pesadas cerca de $0,4 \mathrm{~g}$ de amostra em tubos de centrífuga (peso inicial) revestidos com papel-alumínio. Após a adição de $7 \mathrm{~mL}$ da solução de oxalato de amônio, os tubos foram agitados, em agitador circular, por 2 h.

Extração de óxidos de ferro mais cristalinos e estudo das características cristalográficas da caulinita por DRX

As amostras resultantes da extração com OA foram submetidas ao tratamento com ditionitocitrato-bicarbonato de sódio (DCB) (MEHRA e JACKSON, 1960). As amostras (aproximadamente $0,3 \mathrm{~g})$ foram colocadas em tubos de centrifuga e adicionaram-se soluções de citrato de sódio $0,3 \mathrm{~mol}$ $\mathrm{L}^{-1}$ e de bicarbonato de sódio $1,0 \mathrm{~mol} \mathrm{~L}^{-1}$ (volume final $5,5 \mathrm{~mL}$ ) e $0,13 \mathrm{~g}$ de ditionito de sódio em pó. Os tubos foram mantidos em banho-maria por $30 \mathrm{~min}$ a $60^{\circ} \mathrm{C}$ e, após $15 \mathrm{~min}$ iniciais adicionou-se outra porção de $0,13 \mathrm{~g}$ de ditionito de sódio em pó, tomando-se cuidado de efetuar constantes agitações nos tubos. Realizaram-se mais três etapas de extrações sucessivas com DCB, adotando-se os mesmos procedimentos.

Parte do material desferrificado, composto principalmente por caulinita, foi utilizada para estudos cristalográficos deste mineral por DRX (lâminas orientada e em pó).

\section{Extração de alumínio e aluminossilicato de baixa cristalinidade e gibbsita}

Para extração de alumínio, aluminossilicato de baixa cristalinidade e gibbsita, as amostras desferrificadas (após DCB) foram tratadas com solução de $\mathrm{NaOH} 0,5 \mathrm{~mol} \mathrm{~L}^{-1}$, fervente (JACKSON et al., 1986). Cerca de $0,18 \mathrm{~g}$ de amostra desferrificada foi colocada em tubos de centrífuga. Em paralelo, um copo de béquer de teflon foi aquecido em banhode-areia a $200^{\circ} \mathrm{C}$. Depois de aquecido foi adicionado $7 \mathrm{~mL}$ de $\mathrm{NaOH} 0,5 \mathrm{~mol} \mathrm{~L}^{-1}$ até a solução atingir o ponto de fervura, o que durou em média 7 a $8 \mathrm{~min}$. Nesse instante, a solução fervente de $\mathrm{NaOH}$ foi transferida ao tubo de centrífuga contendo a amostra previamente umedecida com $1 \mathrm{~mL}$ de $\mathrm{NaOH} 0,5 \mathrm{~mol}$ $\mathrm{L}^{-1}$, a frio. Após a agitação manual por $3 \mathrm{~min}$, os respectivos tubos foram imediatamente resfriados em banho com água à temperatura ambiente e a suspensão centrifugada.

\section{Análise termodiferencial (ATD) e análise termogravimétrica (TG) \\ Amostras resultante da extração com DCB foram submetidas às análises térmicas, em um derivatógrafo com saída simultânea dos diagramas de ATD e TG. As amostras foram submetidas ao}

aquecimento a partir da temperatura ambiente até $950^{\circ} \mathrm{C}$ a uma taxa de aquecimento de $10^{\circ} \mathrm{C}$ min $\mathrm{s}^{-1}$ e fluxo de gás de $50 \mathrm{~mL} \mathrm{~min}^{-1}$, sob atmosfera de nitrogênio. Os teores de caulinita e gibbsita foram estimados de acordo com a redução de massa das amostras, em decorrência da desidroxilação dos minerais (TG) (JACKSON, 1979). Após os cálculos, os teores de caulinita e gibbsita foram corrigidos para a fração silte mais argila sem tratamento prévio, considerando a perda de massa da amostra com as extrações com OA e com DCB.

\section{Cálculos mineralógicos da caulinita}

Para o cálculo da distância interplanar no domínio (001) [d(001)] a partir da Lei de Bragg ( $\mathrm{n}=$ 2 dsen $\Theta$ ) foi utilizado o quartzo como padrão interno para corrigir as distorções instrumentais. O diâmetro médio do cristal (DMC) da caulinita (amostra orientada) foi calculado a partir da largura a meia altura (LMA) da reflexão (001), também corrigida pelo padrão interno, utilizando-se a equação de Scherrer (KLUG e ALEXANDER, 1954). Para calcular o índice de cristalinidade da caulinita pelo procedimento apresentado por HUGHES e BROWN (1979) utilizouse a relação da altura da reflexão (020) (valor h1) e a diferença entre a linha de base suspensa formada pelos tripletes na região de 35 a $40^{\circ} 2 \theta$ (radiação CuK $\alpha$ ) e a linha de base real do difratograma de raios-X (valor h2). Detalhes sobre os procedimentos e cálculos podem ser obtidos em MELO et al. (2001a,b).

\section{RESULTADOS E DISCUSSÃO}

De maneira geral, todas as amostras apresentaram baixos teores totais de $\mathrm{Fe}_{2} \mathrm{O}_{3}$ (Tabela 2 ), reflexo dos baixos teores de minerais ferromagnesianos nas rochas de origem dos solos (argilito da Formação Guabirotuba, calcário e granito leucocrático - Tabela 1). Os teores totais de $\mathrm{Al}_{2} \mathrm{O}_{3}$ foram similares entre os horizontes $A$ e $B$, com maiores valores observados para as amostras 33 a 40 (Tabela 2). Os coeficientes de variação (CV) dos teores totais de $\mathrm{Fe}_{2} \mathrm{O}_{3}$ e $\mathrm{Al}_{2} \mathrm{O}_{3}$, entre as repetições (quadrantes), para o horizonte A ou B (mesmo bairro), foram relativamente baixos (valores inferiores a $14,2 \%$ e $11,5 \%$, respectivamente). Os menores CV para os teores totais de $\mathrm{Fe}_{2} \mathrm{O}_{3}$ e $\mathrm{Al}_{2} \mathrm{O}_{3}$ foram observados para os horizontes $\mathrm{A}$ e $\mathrm{B}$ do município de São José dos Pinhais (amostras 33 a 40), cujo material de origem é o granito (CV entre 0,9 e $4 \%$ ) (Tabela 2). A possibilidade de mudanças locais na composição química das rochas de origem das amostras 1 a 24 (argilito) e das amostras 25 a 32 (calcário) é maior, devido a maior heterogeneidade do ambiente sedimentar. O granito é formado diretamente do resfriamento do magma, em uma ambiente mais confinado e de características químicas mais homogêneas (POPP, 1987). As médias dos valores de $\mathrm{CV}$ para os horizontes $\mathrm{A}$ e $\mathrm{B}$ foram próximas, indicando que o grau de pedogênese não interferiu na variação dos óxidos de Fe e de Al. 
BARBAR, L.C. e MELO, V.F. Variabilidade das características químicas...

TABELA 2 - Teores totais de óxidos de Fe e Al e elementos traços na fração silte mais argila.

\begin{tabular}{|c|c|c|c|c|c|c|c|c|c|c|}
\hline Amostra & Notação & \multicolumn{3}{|c|}{$-----g_{k g}{ }^{-1}----$} & $\mathrm{Zn}$ & $\mathrm{Mn}$ & $\begin{array}{c}\mathrm{Cu} \\
\mathrm{ng} \mathrm{kg} \\
\end{array}$ & $\mathrm{Ni}$ & $\mathrm{Pb}$ & $\mathrm{Cr}$ \\
\hline 1 & $1-1 A$ & 38,4 & 248,4 & 1375,3 & 23,1 & 272,7 & 101,7 & 7,8 & 7,2 & 34,5 \\
\hline 2 & $1-2 A$ & 38,2 & 255,3 & 1784,1 & 63,9 & 264,6 & 138,1 & 8,3 & 15,0 & 31,1 \\
\hline 3 & $1-3 A$ & 40,9 & 244,3 & 1532,3 & 11,2 & 302,5 & 68,0 & 8,1 & 1,7 & 32,3 \\
\hline 4 & $1-4 A$ & 41,9 & 293,2 & 1742,5 & 15,6 & 312,5 & 62,7 & 9,8 & 20,6 & 35,1 \\
\hline \multirow{2}{*}{\multicolumn{2}{|c|}{$\begin{array}{l}\text { Média }_{(1)} \\
\text { CV(\%) }\end{array}$}} & 39,9 & 260,3 & 1608,6 & 28,5 & 288,1 & 92,6 & 8,5 & 11,1 & 33,3 \\
\hline & & 4,6 & 8,6 & 11,8 & 84,8 & 8,0 & 37,7 & 10,5 & 75,0 & 5,6 \\
\hline 5 & $1-1 B$ & 48,5 & 258,3 & 842,6 & 11,0 & 192,9 & 28,1 & 6,6 & 3,6 & 29,2 \\
\hline 6 & $1-2 B$ & 55,0 & 271,4 & 1688,4 & 6,8 & 245,8 & 91,6 & 6,8 & 8,3 & 35,3 \\
\hline 7 & $1-3 B$ & 62,1 & 319,8 & 1019,3 & 9,2 & 305,0 & 23,2 & 7,3 & 26,5 & 37,9 \\
\hline 8 & $1-4 B$ & 62,2 & 311,7 & 931,9 & 3,6 & 361,2 & 53,7 & 7,2 & 14,8 & 39,4 \\
\hline \multirow{2}{*}{\multicolumn{2}{|c|}{$\begin{array}{l}\text { Média } \\
\text { CV(\%) }\end{array}$}} & 57,0 & 290,3 & 1120,6 & 7,7 & 276,2 & 49,2 & 7,0 & 13,3 & 35,5 \\
\hline & & 11,5 & 10,4 & 34,4 & 41,9 & 26,4 & 63,7 & 4,7 & 74,6 & 12,7 \\
\hline 9 & $2-1 A$ & 48,0 & 229,4 & 3045,0 & 54,9 & 733,1 & 77,2 & 21,0 & 17,9 & 42,9 \\
\hline 10 & $2-2 A$ & 49,9 & 246,7 & 3245,4 & 21,6 & 421,5 & 66,0 & 16,2 & 14,9 & 44,0 \\
\hline 11 & $2-3 A$ & 49,1 & 303,5 & 3458,9 & 28,5 & 498,1 & 71,3 & 17,7 & 22,3 & 46,5 \\
\hline 12 & $2-4 A$ & 47,1 & 229,9 & 3026,4 & 26,3 & 431,5 & 62,6 & 17,4 & 16,5 & 45,1 \\
\hline \multicolumn{2}{|l|}{ Média } & 48,5 & 252,4 & 3193,9 & 32,8 & 521,1 & 69,3 & 18,1 & 17,9 & 44,6 \\
\hline \multicolumn{2}{|l|}{$\mathrm{CV}(\%)$} & 2,5 & 13,9 & 6,3 & 45,7 & 27,9 & 9,2 & 11,4 & 17,8 & 3,4 \\
\hline 13 & $2-1 B$ & 59,6 & 250,9 & 3074,0 & 16,7 & 1627,9 & 95,0 & 32,4 & 21,9 & 42,4 \\
\hline 14 & $2-2 B$ & 58,1 & 194,5 & 2841,5 & 15,8 & 1418,2 & 102,6 & 33,9 & 23,8 & 40,8 \\
\hline 15 & 2-3B & 60,3 & 242,4 & 3098,4 & 19,2 & 1182,0 & 98,4 & 29,8 & 20,2 & 44,4 \\
\hline 16 & $2-4 B$ & 62,5 & 253,4 & 3255,0 & 19,3 & 946,8 & 94,1 & 22,5 & 24,6 & 45,4 \\
\hline \multicolumn{2}{|l|}{ Média } & 60,1 & 235,3 & 3067,2 & 17,8 & 1293,7 & 97,5 & 29,7 & 22,6 & 43,3 \\
\hline \multicolumn{2}{|l|}{ CV(\%) } & 3,0 & 11,7 & 5,6 & 10,0 & 22,8 & 4,0 & 17,1 & 8,7 & 4,8 \\
\hline 17 & $3-1 A$ & 60,1 & 364,2 & 2414,2 & 15,1 & 312,8 & 73,1 & 27,0 & 7,9 & 63,0 \\
\hline 18 & $3-2 A$ & 56,2 & 354,8 & 2121,9 & 12,9 & 261,0 & 76,0 & 21,2 & 12,4 & 54,1 \\
\hline 19 & $3-3 A$ & 60,0 & 332,7 & 2134,6 & 11,4 & 271,7 & 66,4 & 23,4 & 14,0 & 59,0 \\
\hline 20 & $3-4 A$ & 46,5 & 369,3 & 2322,1 & 16,5 & 228,2 & 57,4 & 19,7 & 21,1 & 49,3 \\
\hline \multicolumn{2}{|l|}{ Média } & 55,7 & 355,3 & 2248,2 & 14,0 & 268,4 & 68,2 & 22,8 & 13,9 & 56,4 \\
\hline \multicolumn{2}{|l|}{ CV(\%) } & 11,5 & 4,6 & 6,4 & 16,2 & 13,0 & 12,1 & 13,9 & 39,6 & 10,5 \\
\hline 21 & $3-1 B$ & 67,8 & 310,8 & 1103,3 & 3,1 & 130,8 & 54,2 & 12,8 & 8,0 & 66,8 \\
\hline 22 & $3-2 B$ & 71,5 & 339,8 & 1085,4 & 3,7 & 135,1 & 58,1 & 13,9 & 5,6 & 70,4 \\
\hline 23 & $3-3 B$ & 86,2 & 345,8 & 1147,9 & 3,2 & 138,0 & 71,5 & 14,3 & 13,5 & 72,8 \\
\hline 24 & $3-4 B$ & 62,3 & 330,8 & 1212,1 & 3,4 & 132,2 & 91,2 & 15,3 & 4,8 & 66,4 \\
\hline \multicolumn{2}{|l|}{ Média } & 72,0 & 331,8 & 1137,2 & 3,4 & 134,0 & 68,8 & 14,1 & 8,0 & 69,1 \\
\hline \multicolumn{2}{|l|}{ CV(\%) } & 14,2 & 4,6 & 5,0 & 7,9 & 2,4 & 24,3 & 7,3 & 49,2 & 4,4 \\
\hline 25 & $4-1 A$ & 50,4 & 278,4 & 3712,8 & 26,3 & 260,3 & 42,4 & 16,2 & 8,9 & 56,0 \\
\hline 26 & $4-2 A$ & 45,9 & 283,2 & 3786,2 & 19,3 & 235,5 & 36,5 & 12,4 & 9,1 & 47,4 \\
\hline 27 & $4-3 A$ & 47,5 & 311,4 & 4585,2 & 22,7 & 249,3 & 35,8 & 14,2 & 12,5 & 50,3 \\
\hline 28 & 4-4A & 52,2 & 256,2 & 4794,0 & 24,4 & 287,5 & 39,0 & 16,0 & 14,0 & 57,3 \\
\hline \multicolumn{2}{|l|}{ Média } & 49,0 & 282,3 & 4219,6 & 23,2 & 258,2 & 38,4 & 14,7 & 11,1 & 52,8 \\
\hline CV(\%) & & 5,8 & 8,0 & 13,0 & 12,8 & 8,5 & 7,8 & 12,1 & 22,7 & 8,9 \\
\hline 29 & $4-1 B$ & 52,4 & 231,6 & 2129,3 & 31,2 & 274,0 & 114,3 & 13,1 & 5,2 & 58,5 \\
\hline 30 & $4-2 B$ & 55,5 & 253,2 & 2178,2 & 8,2 & 245,2 & 96,1 & 12,0 & 14,8 & 54,9 \\
\hline 31 & $4-3 B$ & 48,0 & 228,7 & 2004,0 & 9,1 & 246,9 & 110,1 & 11,0 & 4,1 & 50,8 \\
\hline 32 & $4-4 B$ & 46,9 & 237,7 & 2042,8 & 7,1 & 221,6 & 89,8 & 9,9 & 2,4 & 49,2 \\
\hline Média & & 50,7 & 237,8 & 2088,6 & 13,9 & 246,9 & 102,6 & 11,5 & 6,6 & 53,4 \\
\hline CV(\%) & & 7,9 & 4,6 & 3,8 & 83,2 & 8,7 & 11,2 & 11,9 & 84,1 & 7,9 \\
\hline 33 & $5-1 A$ & 74,3 & 399,1 & 1570,6 & 6,3 & 317,3 & 56,5 & 34,5 & 2,8 & 114,9 \\
\hline 34 & $5-2 A$ & 74,1 & 368,3 & 1372,8 & 5,8 & 311,7 & 65,4 & 32,6 & 2,7 & 112,0 \\
\hline 35 & $5-3 A$ & 73,2 & 380,8 & 1533,9 & 6,9 & 307,1 & 59,3 & 36,0 & 2,5 & 119,5 \\
\hline 36 & $5-4 A$ & 72,9 & 368,9 & 1369,2 & 6,0 & 405,9 & 60,1 & 37,2 & 6,9 & 109,5 \\
\hline Média & & 73,6 & 379,3 & 1461,6 & 6,3 & 335,5 & 60,3 & 35,1 & 3,7 & 114,0 \\
\hline CV(\%) & & 0,9 & 3,8 & 7,2 & 7,7 & 14,0 & 6,2 & 5,7 & 56,9 & 3,8 \\
\hline 37 & $5-1 B$ & 89,1 & 387,5 & 837,5 & 2,3 & 187,8 & 96,9 & 37,8 & 6,7 & 111,7 \\
\hline 38 & $5-2 B$ & 85,9 & 365,4 & 860,1 & 10,3 & 197,3 & 46,8 & 36,3 & 16,1 & 125,3 \\
\hline 39 & $5-3 B$ & 86,3 & 352,1 & 802,4 & 3,2 & 205,6 & 124,3 & 37,7 & 5,5 & 114,6 \\
\hline 40 & $5-4 B$ & 85,9 & 365,6 & 809,2 & 3,7 & 205,2 & 51,9 & 37,0 & 23,4 & 105,8 \\
\hline Média & & 86,8 & 367,7 & 827,3 & 4,9 & 199,0 & 80,0 & 37,2 & 12,9 & 114,4 \\
\hline CV(\%) & & 1,8 & 4,0 & 3,2 & 75,1 & 4,2 & 46,4 & 1,9 & 65,3 & 7,1 \\
\hline CV médio & riz. $A(\%)$ & 5,1 & 7,8 & 9,0 & 33,5 & 14,3 & 14,6 & 10,7 & 42,4 & 6,5 \\
\hline CV médio & riz. B(\%) & 7,7 & 7,1 & 10,4 & 43,6 & 12,9 & 29,9 & 8,6 & 56,4 & 7,4 \\
\hline CV médio & $\mathrm{ral}(\%)$ & 6,4 & 7,4 & 9,7 & 38,5 & 13,6 & 22,3 & 9,6 & 49,4 & 6,9 \\
\hline
\end{tabular}

${ }^{\text {(1) }}$ Média de 4 repetições; ${ }^{(2)} \mathrm{CV}$ - coeficiente de variação. 
Os valores de CV para os demais metais (elementos acessórios na composição dos minerais e rochas) foram maiores, com valores máximos para o $\mathrm{Pb}$ e para o $\mathrm{Zn}$ (CV médio iguais a $49,4 \%$ e $38,5 \%$, respectivamente) (Tabela 2 ). Contudo, deve-se considerar possíveis contribuições de atividades inerentes ao ambiente urbano nas variações locais dos teores de $\mathrm{Mg}, \mathrm{Zn}, \mathrm{Cu}, \mathrm{Ni}, \mathrm{Pb}$ e $\mathrm{Cr}$, como adubações, adições de lixos e resíduos, emissões de escapamentos dos carros, etc., principalmente para o horizonte A dos solos.

Os teores de óxidos de ferro e de alumínio de baixa cristalinidade, extraídos pelo oxalato de amônio (OA), variaram de 0,1 a $6,5 \mathrm{~g} \mathrm{~kg}^{-1}$ e de $0,1 \mathrm{a}$ $10,2 \mathrm{~g} \mathrm{~kg}^{-1}$, respectivamente (Tabela 3 ). Esses teores baixos indicam que os solos têm predomínio de formas de óxidos de ferro mais cristalinas (por exemplo, hematita e goethita). A relação $\mathrm{Fe}_{2} \mathrm{O}_{3}-\mathrm{OA} /$ $\mathrm{Fe}_{2} \mathrm{O}_{3}$-DCB reflete diretamente a proporção entre óxidos secundários de ferro de baixa (maiores valores) e alta cristalinidade (menores valores) (KÄMPF et al., 1988; FONTES e WEED, 1991). No presente estudo, os valores para essa relação foram inferiores a 0,147, com valor médio de 0,047. De forma análoga, os baixos teores de $\mathrm{Al}_{2} \mathrm{O}_{3}$ extraídos pela solução de $\mathrm{NaOH} 0,5 \mathrm{~mol} \mathrm{~L}^{-1}$ fervente (Tabela 3 ), indicam inexpressiva ocorrência de minerais aluminossilicatos de baixa cristalinidade, principalmente porque esse método não consegue separar de forma eficiente as formas amorfas e cristalinas dos minerais. Segundo MELO et al. (2002), o material dissolvido pelo $\mathrm{NaOH} 0,5 \mathrm{~mol} \mathrm{~L}$ ${ }^{1}$ fervente é constituído, predominantemente, por caulinita de pior cristalinidade e gibbsita, com pequena participação de aluminossilicatos amorfos. Os maiores teores de $\mathrm{Al}_{2} \mathrm{O}_{3}$ extraído com solução de $\mathrm{NaOH}$ (Tabela 3) e de gibbsita (Tabela 4) foram verificados para as mesma amostras: 5 a 8; 21 a 24 e 37 a 40. A grande diferença entre a soma dos teores de $\mathrm{Fe}_{2} \mathrm{O}_{3}$ e $\mathrm{Al}_{2} \mathrm{O}_{3}$ e a redução em massa da amostra pelos tratamentos com OA e $\mathrm{NaOH}$ (Tabela 3) é devida a presença de outros óxidos não determinados (p. ex. $\mathrm{SiO}_{2}$ ) e a grande quantidade de água dos minerais de baixa cristalinidade. A água de constituição desses materiais pode estar sob diversas formas: absorvida entre 105 e $150{ }^{\circ} \mathrm{C}$ (JACKSON, 1979) e de cristalização. Por exemplo, a ferrihidrita, um óxido de $\mathrm{Fe}$ amorfo hidratado $\left(2,5 \mathrm{Fe}_{2} \mathrm{O}_{3} .4,5 \mathrm{H}_{2} \mathrm{O}\right)$, precursor da hematita (SCHWERTMANN e TAYLOR, 1989), apresenta 17\% de água estrutural (JACKSON, 1979).

Devido aos baixos teores de $\mathrm{Fe}_{2} \mathrm{O}_{3}-\mathrm{OA}$ e de $\mathrm{Al}_{2} \mathrm{O}_{3}-\mathrm{OA}$ e de $\mathrm{Al}_{2} \mathrm{O}_{3}-\mathrm{NaOH}$, torna-se imprecisa a associação entre local de amostragem em um mesmo sítio (repetições) e variações nos teores de elementos. Para teores muito baixos, os erros analíticos e instrumentais são mais expressivos. Os teores de $\mathrm{Fe}_{2} \mathrm{O}_{3}-\mathrm{OA}$, na maioria das amostras, foram iguais à zero, o que não permitiu o cálculo do CV (Tabela 3). Dessa forma, o parâmetro mais confiável para estimar o CV da quantidade de minerais de baixa cristalinidade no solo é a perda de massa da amostra em função do tratamento com
OA: método mais seletivo para essa classe de minerais e determinação da perda de massa por pesagem direta da amostra seca em estufa, antes e após o tratamento. Os CV da redução de massa dos minerais de baixa cristalinidade (OA), independente do material de origem e do horizonte do solo (Tabela 3 ), foram consistentemente superiores aos CV dos teores totais de $\mathrm{Fe}_{2} \mathrm{O}_{3}$ e $\mathrm{Al}_{2} \mathrm{O}_{3}$ (Tabela 2). De fato, esperam-se maiores variações locais nos minerais de baixa cristalinidade, pois sua formação está mais relacionada a condições específicas do solo, as quais podem mudar em curtas distâncias horizontais: umidade, teor de matéria orgânica, atividade biológica, $\mathrm{pH}$, etc.

Os teores de $\mathrm{Fe}_{2} \mathrm{O}_{3}$-DCB variaram de 40,0 a $99,4 \mathrm{~g} \mathrm{~kg}^{-1}$ (Tabela 3 ), refletindo uma pequena divergência dos materiais de origem dos solos quanto aos teores do elemento. Como evidência da associação direta entre natureza do material de origem (teor de minerais primários ferromagnesianos) e teores de hematita e goethita na fração argila dos solos, GHIDIN et al. (2006) encontraram teores bem superiores de $\mathrm{Fe}_{2} \mathrm{O}_{3}-\mathrm{DCB}$ no horizonte $\mathrm{B}$ de solos originados de rochas básicas no Paraná (teor máximo de $280 \mathrm{~g} \mathrm{~kg}^{-1}$ ). Conforme discutido anteriormente, a possibilidade de variações locais nos minerais cristalinos é menor, o que justifica os baixos valores de CV para os teores de $\mathrm{Fe}_{2} \mathrm{O}_{3}-\mathrm{DCB}$ (Tabela 3). $\mathrm{O} \mathrm{Al^{3+ }}$ extraído pelo $\mathrm{DCB}$ (teor de $\mathrm{Al}_{2} \mathrm{O}_{3}$ - Tabela 3) encontra-se na estrutura dos óxidos de ferro cristalinos (hematita e goethita), substituindo isomorficamente o $\mathrm{Fe}^{3+}$ (BIGHAM et al., 1978; CURI e FRANZMEIER, 1984; SCHWERTMANN e KÄMPF, 1985, MELO et al., 2001a).

A difratometria de raios-X (DRX) e a análise termogravimétrica da fração silte mais argila revelaram composição mineralógica muito similar entre os horizontes dos solos. $\mathrm{Na}$ análise quantitativa (Tabela 4) verificou-se o predomínio de caulinita, seguida de proporções menores de gibbsita, o que indica solos pouco intemperizados (Cambissolos). A soma das quantidades dos minerais (caulinita + gibbsita + material amorfo extraído pelo $O A$ - perda de massa da amostra) ficou entre 335,0 e $687,8 \mathrm{~g} \mathrm{~kg}^{-1}$. A diferença para $1000 \mathrm{~g}$ $\mathrm{kg}^{-1}$ se deve aos minerais não quantificados, principalmente ao quartzo, mineral abundante na fração silte, em função da alta intensidade das reflexões do mineral por DRX. Devido a grande resistência ao intemperismo, o quartzo tende a permanecer nas frações mais grosseiras do solo (neste caso, fração silte). Além do quartzo, outros minerais foram identificados por DRX: hematita, goethita, mica e minerais secundários do tipo 2:1. Mais uma vez, confirmam-se os baixos valores para o CV de minerais cristalinos (Tabela 4): os teores de caulinita e gibbsita foram mais homogêneos a curtas distâncias horizontais dos solos. Nos solos originados de argilito da Formação Guabirotuba, verificou-se maior variação nos teores de caulinita e gibbsita em subsuperfície. Esse comportamento, possivelmente, pode ser atribuído ao menor grau de intemperismo do horizonte $B$ e a elevada 
BARBAR, L.C. e MELO, V.F. Variabilidade das características químicas...

TABELA 3 - Teores de $\mathrm{Fe}_{2} \mathrm{O}_{3}$ e $\mathrm{Al}_{2} \mathrm{O}_{3}$ de minerais de baixa cristalinidade (extração com oxalato de amônio - OA

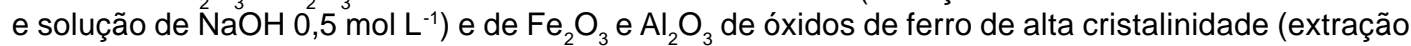
com ditionito-citrato-bicarbonato - DCB) na fração silte mais argila.

\begin{tabular}{|c|c|c|c|c|c|c|c|c|c|c|}
\hline \multirow{3}{*}{ Amostra } & \multirow{3}{*}{ Notação } & \multicolumn{3}{|c|}{$\mathrm{OA}$} & \multicolumn{3}{|c|}{ DCB } & \multicolumn{3}{|c|}{$\mathrm{NaOH}$} \\
\hline & & $\mathrm{Fe}_{2} \mathrm{O}_{3}$ & $\mathrm{Al}_{2} \mathrm{O}_{3}$ & $\begin{array}{c}\text { Perda } \\
\text { Massa }^{(1)}\end{array}$ & $\mathrm{Fe}_{2} \mathrm{O}_{3}$ & $\mathrm{Al}_{2} \mathrm{O}_{3}$ & $\begin{array}{c}\text { Perda } \\
\text { Massa }^{(1)}\end{array}$ & $\mathrm{Fe}_{2} \mathrm{O}_{3}$ & $\mathrm{Al}_{2} \mathrm{O}_{3}$ & $\begin{array}{c}\text { Perda } \\
\text { Massa }^{(1)}\end{array}$ \\
\hline & & \multicolumn{9}{|c|}{ 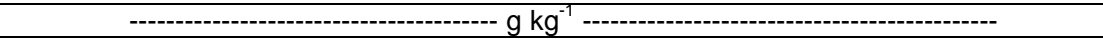 } \\
\hline 1 & $1-1 \mathrm{~A}$ & 2,9 & 4,7 & 34 & 46,6 & 18,7 & 107 & 0,1 & 14,1 & 47 \\
\hline 2 & $1-2 A$ & 3,0 & 5,3 & 28 & 47,6 & 19,4 & 99 & 0,0 & 8,9 & 42 \\
\hline 3 & $1-3 A$ & 3,4 & 5,4 & 34 & 44,5 & 17,5 & 105 & 0,1 & 10,8 & 47 \\
\hline 4 & $1-4 \mathrm{~A}$ & 3,0 & 5,3 & 25 & 50,3 & 20,4 & 115 & 0,0 & 15,6 & 45 \\
\hline Média $^{(2)}$ & & 3,1 & 5,2 & 30 & 47,3 & 19,0 & 107 & nd & 12,4 & 45 \\
\hline $\mathrm{CV}(\%)^{(3)}$ & & 7,1 & 6,0 & 14,9 & 5,1 & 6,4 & 6,2 & nd & 24,7 & 5,2 \\
\hline 5 & $1-1 \mathrm{~B}$ & 3,8 & 6,7 & 30 & 59,1 & 17,3 & 122 & 0,0 & 23,7 & 61 \\
\hline 6 & $1-2 B$ & 4,1 & 8,1 & 38 & 50,1 & 15,7 & 111 & 0,0 & 16,2 & 36 \\
\hline 7 & $1-3 B$ & 3,9 & 8,1 & 31 & 61,9 & 17,4 & 115 & 0,0 & 20,9 & 47 \\
\hline 8 & $1-4 \mathrm{~B}$ & 2,7 & 6,4 & 28 & 63,5 & 17,3 & 122 & 0,0 & 24,5 & 56 \\
\hline Média & & 3,6 & 7,3 & 32 & 58,7 & 16,9 & 118 & nd & 21,3 & 50 \\
\hline CV(\%) & & 16,7 & 12,1 & 13,7 & 10,2 & 4,8 & 4,6 & nd & 17,6 & 22,0 \\
\hline 9 & $2-1 A$ & 4,6 & 6,6 & 37 & 46,0 & 19,9 & 128 & 0,0 & 6,2 & 45 \\
\hline 10 & $2-2 A$ & 6,1 & 9,4 & 46 & 45,4 & 20,8 & 130 & 0,0 & 10,1 & 41 \\
\hline 11 & $2-3 A$ & 6,5 & 10,2 & 35 & 44,1 & 19,2 & 140 & 0,2 & 9,6 & 49 \\
\hline 12 & $2-4 A$ & 5,2 & 8,0 & 36 & 43,7 & 19,7 & 131 & 0,1 & 9,7 & 42 \\
\hline Média & & 5,6 & 8,6 & 39 & 44,8 & 19,9 & 132 & nd & 8,9 & 44 \\
\hline CV(\%) & & 15,4 & 18,5 & 13,2 & 2,4 & 3,4 & 4,0 & nd & 20,4 & 8,1 \\
\hline 13 & $2-1 B$ & 2,0 & 7,1 & 47 & 48,2 & 16,9 & 92 & 0,0 & 10,0 & 53 \\
\hline 14 & $2-2 B$ & 0,7 & 3,1 & 73 & 50,8 & 18,2 & 65 & 0,0 & 10,8 & 63 \\
\hline 15 & $2-3 B$ & 0,6 & 2,4 & 45 & 49,2 & 17,0 & 97 & 0,0 & 10,0 & 47 \\
\hline 16 & $2-4 B$ & 1,1 & 2,9 & 55 & 50,5 & 19,0 & 97 & 0,0 & 9,7 & 44 \\
\hline Média & & 1,1 & 3,9 & 55 & 49,7 & 17,8 & 88 & nd & 10,1 & 52 \\
\hline CV(\%) & & 55,9 & 57,0 & 23,2 & 2,4 & 5,7 & 17,5 & nd & 4,7 & 16,2 \\
\hline 17 & $3-1 A$ & 5,5 & 7,0 & 57 & 53,7 & 24,1 & 126 & 0,0 & 17,0 & 55 \\
\hline 18 & $3-2 A$ & 3,4 & 4,5 & 51 & 53,6 & 24,3 & 124 & 0,0 & 17,5 & 55 \\
\hline 19 & $3-3 A$ & 1,9 & 2,3 & 59 & 51,3 & 22,9 & 127 & 0,1 & 16,3 & 59 \\
\hline 20 & $3-4 A$ & 6,2 & 7,7 & 53 & 51,0 & 22,9 & 129 & 0,0 & 13,7 & 53 \\
\hline Média & & 4,2 & 5,4 & 55 & 52,4 & 23,6 & 127 & nd & 16,1 & 56 \\
\hline CV $(\%)$ & & 46,5 & 46,1 & 6,6 & 2,8 & 3,2 & 1,6 & nd & 10,5 & 4,5 \\
\hline 21 & 3-1B & 3,1 & 5,3 & 43 & 71,6 & 29,3 & 148 & 0,3 & 21,0 & 63 \\
\hline 22 & $3-2 B$ & 1,2 & 2,9 & 77 & 72,0 & 28,7 & 135 & 0,1 & 20,6 & 56 \\
\hline 23 & $3-3 B$ & 1,5 & 3,2 & 40 & 91,9 & 35,6 & 181 & 0,1 & 25,5 & 69 \\
\hline 24 & $3-4 \mathrm{~B}$ & 2,7 & 3,7 & 59 & 56,7 & 24,4 & 117 & 0,0 & 21,0 & 63 \\
\hline Média & & 2,1 & 3,8 & 55 & 73,1 & 29,5 & 145 & nd & 22,0 & 63 \\
\hline CV(\%) & & 44,4 & 28,7 & 31,1 & 19,8 & 15,6 & 18,6 & nd & 10,6 & 8,5 \\
\hline 25 & $4-1 \mathrm{~A}$ & 0,2 & 0,4 & 52 & 51,5 & 28,3 & 159 & 0,0 & 10,6 & 43 \\
\hline 26 & $4-2 A$ & 0,2 & 0,4 & 59 & 48,5 & 26,5 & 153 & 0,1 & 11,3 & 43 \\
\hline 27 & $4-3 A$ & 0,1 & 0,1 & 54 & 49,5 & 27,4 & 157 & 0,0 & 11,3 & 50 \\
\hline 28 & $4-4 A$ & 0,1 & 0,1 & 48 & 48,8 & 26,4 & 156 & 0,0 & 9,0 & 40 \\
\hline Média & & 0,1 & 0,2 & 53 & 49,6 & 27,2 & 156 & nd & 10,6 & 44 \\
\hline CV(\%) & & 80,6 & 83,1 & 8,6 & 2,7 & 3,3 & 1,6 & nd & 10,3 & 9,6 \\
\hline 29 & $4-1 B$ & 0,1 & 0,1 & 29 & 40,0 & 14,9 & 99 & 0,0 & 11,7 & 46 \\
\hline 30 & $4-2 B$ & 0,1 & 0,2 & 19 & 42,4 & 15,7 & 102 & 0,0 & 10,7 & 40 \\
\hline 31 & $4-3 B$ & 1,5 & 5,2 & 34 & 41,5 & 14,5 & 98 & 0,0 & 9,3 & 31 \\
\hline 32 & $4-4 \mathrm{~B}$ & 1,8 & 5,0 & 35 & 41,2 & 14,8 & 89 & 0,2 & 9,0 & 37 \\
\hline Média & & 0,9 & 2,6 & 29 & 41,3 & 15,0 & 97 & nd & 10,2 & 39 \\
\hline CV(\%) & & 109,7 & 109,6 & 25,0 & 2,4 & 3,4 & 5,8 & nd & 12,4 & 16,2 \\
\hline 33 & $5-1 \mathrm{~A}$ & 3,3 & 5,4 & 36 & 66,0 & 26,6 & 162 & 0,0 & 14,9 & 43 \\
\hline 34 & $5-2 A$ & 2,9 & 4,6 & 33 & 80,6 & 33,7 & 182 & 0,0 & 14,8 & 42 \\
\hline 35 & $5-3 A$ & 3,4 & 5,4 & 35 & 78,1 & 32,2 & 184 & 0,1 & 17,9 & 48 \\
\hline 36 & $5-4 A$ & 4,1 & 5,8 & 37 & 87,7 & 36,8 & 184 & 0,0 & 17,1 & 42 \\
\hline Média & & 3,4 & 5,3 & 35 & 78,1 & 32,3 & 178 & nd & 16,2 & 44 \\
\hline CV(\%) & & 14,3 & 9,9 & 4,8 & 11,6 & 13,2 & 6,0 & nd & 9,7 & 6,6 \\
\hline 37 & $5-1 \mathrm{~B}$ & 0,9 & 3,3 & 26 & 99,0 & 24,6 & 176 & 0,1 & 22,9 & 5,5 \\
\hline 38 & $5-2 B$ & 1,1 & 4,2 & 33 & 98,5 & 26,3 & 197 & 0,0 & 22,1 & 5,8 \\
\hline 39 & $5-3 B$ & 1,3 & 4,3 & 26 & 99,4 & 23,1 & 177 & 0,0 & 26,3 & 5,2 \\
\hline 40 & $5-4 \mathrm{~B}$ & 0,9 & 3,3 & 24 & 97,8 & 23,2 & 182 & 0,0 & 30,3 & 6,1 \\
\hline Média & & 1,1 & 3,8 & 27 & 98,7 & 24,3 & 183 & nd & 25,4 & 5,7 \\
\hline CV(\%) & & 17,6 & 14,3 & 14,5 & 0,7 & 6,2 & 5,3 & nd & 14,7 & 6,9 \\
\hline CV médio & $\mathrm{A}(\%)$ & 32,8 & 32,7 & 9,6 & 4,9 & 5,9 & 3,9 & nd & 15,1 & 6,8 \\
\hline CV médio & B (\%) & 48,9 & 44,4 & 21,5 & 7,1 & 7,1 & 10,4 & nd & 12,0 & 13,9 \\
\hline CV médio & I (\%) & 40,8 & 38,5 & 15,6 & 6,0 & 6,5 & 7,1 & nd & 13,5 & 10,4 \\
\hline
\end{tabular}

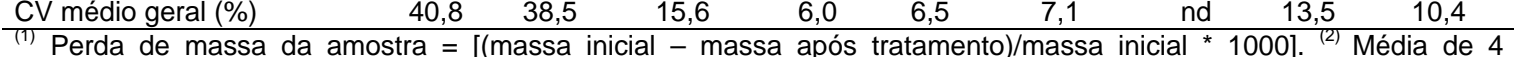
repetições; ${ }^{(3)} \mathrm{CV}$ - coeficiente de variação. 
BARBAR, L.C. e MELO, V.F. Variabilidade das características químicas...

TABELA 4 - Composição mineralógica e características cristalográficas da caulinita (Ct) e temperatura de desidroxilação (TD) da Ct e da gibbsita $(\mathrm{Gb})$ na fração silte mais argila(1)

\begin{tabular}{|c|c|c|c|c|c|c|c|c|c|}
\hline \multirow{3}{*}{ Amostra } & \multirow{3}{*}{ Notação } & & & \multicolumn{4}{|c|}{ Características cristalográficas da Ct } & \multirow[b]{2}{*}{ TD Ct } & \multirow[b]{2}{*}{$\mathrm{TD} G \mathrm{~b}$} \\
\hline & & $\mathrm{Ct}$ & $\mathrm{Gb}$ & $d(001)$ & $\operatorname{LMH}(001)$ & $\operatorname{DMC}(001)$ & $\mathrm{ICHB}$ & & \\
\hline & & $----g_{k g}$ & ---- & $\mathrm{nm}$ & $\stackrel{02}{2 \theta}$ & $\mathrm{nm}$ & & ${ }^{\circ} \mathrm{C}$ & ${ }^{\circ} \mathrm{C}$ \\
\hline 1 & $1-1 \mathrm{~A}$ & 397,5 & 69,9 & 0,718 & 3,8 & 25,3 & 10,7 & 478,1 & 261,8 \\
\hline 2 & $1-2 A$ & 353,1 & 62,2 & 0,721 & 3,5 & 33,5 & 10,4 & 470,0 & 252,5 \\
\hline 3 & $1-3 A$ & 392,5 & 71,4 & 0,716 & 3,7 & 29,3 & 9,7 & 476,9 & 260,8 \\
\hline 4 & $1-4 \mathrm{~A}$ & 384,9 & 73,4 & 0,721 & 3,8 & 26,6 & 9,7 & 472,0 & 253,7 \\
\hline Média $^{(2)}$ & & 382,0 & 69,2 & 0,719 & 3,7 & 28,7 & 10,1 & 474,3 & 257,2 \\
\hline $\mathrm{CV}(\%)^{(3)}$ & & 5,2 & 7,1 & 0,353 & 3,6 & 12,6 & 5,0 & 0,8 & 1,9 \\
\hline 5 & $1-1 \mathrm{~B}$ & 449,8 & 101,7 & 0,713 & 3,5 & 29,4 & 10,3 & 484,3 & 257,0 \\
\hline 6 & $1-2 B$ & 370,0 & 71,7 & 0,718 & 3,7 & 28,2 & 10,0 & 481,8 & 254,3 \\
\hline 7 & $1-3 B$ & 449,7 & 96,8 & 0,716 & 3,5 & 30,7 & 10,2 & 485,0 & 256,7 \\
\hline 8 & $1-4 \mathrm{~B}$ & 489,4 & 110,4 & 0,721 & 3,5 & 30,7 & 11,1 & 485,1 & 260,2 \\
\hline Média & & 439,7 & 95,2 & 0,717 & 3,6 & 29,8 & 10,4 & 484,1 & 257,1 \\
\hline CV(\%) & & 11,4 & 17,5 & 0,475 & 2,8 & 4,0 & 4,6 & 0,3 & 0,9 \\
\hline 9 & $2-1 A$ & 349,7 & 68,0 & 0,721 & 4,0 & 25,1 & 9,9 & 465,9 & 256,4 \\
\hline 10 & $2-2 A$ & 317,0 & 60,9 & 0,721 & 6,5 & 13,3 & 9,3 & 462,7 & 250,9 \\
\hline 11 & $2-3 A$ & 311,4 & 60,0 & 0,718 & 5,5 & 16,2 & 9,5 & 464,3 & 253,6 \\
\hline 12 & $2-4 A$ & 299,0 & 55,8 & 0,721 & 5,0 & 17,5 & 9,4 & 458,0 & 246,9 \\
\hline Média & & 319,3 & 61,2 & 0,720 & 5,3 & 18,0 & 9,5 & 462,7 & 252,0 \\
\hline CV(\%) & & 6,8 & 8,3 & 0,183 & 19,8 & 27,9 & 2,8 & 0,7 & 1,6 \\
\hline 13 & $2-1 \mathrm{~B}$ & 340,0 & 62,0 & 0,721 & 6,0 & 15,3 & 9,2 & 459,1 & 249,7 \\
\hline 14 & $2-2 B$ & 364,7 & 65,4 & 0,719 & 7,7 & 11,0 & 9,1 & 463,3 & 248,8 \\
\hline 15 & $2-3 B$ & 471,5 & 80,9 & 0,716 & 6,5 & 13,3 & 9,0 & 467,3 & 260,1 \\
\hline 16 & $2-4 B$ & 328,7 & 77,0 & 0,719 & 6,3 & 14,4 & 8,9 & 466,1 & 254,7 \\
\hline Média & & 376,2 & 71,3 & 0,719 & 6,6 & 13,5 & 9,1 & 464,0 & 253,3 \\
\hline CV(\%) & & 17,3 & 12,7 & 0,313 & 11,3 & 13,8 & 1,4 & 0,8 & 2,1 \\
\hline 17 & $3-1 A$ & 413,8 & 99,7 & 0,726 & 4,0 & 24,4 & 10,0 & 462,1 & 250,9 \\
\hline 18 & $3-2 A$ & 391,9 & 106,4 & 0,724 & 4,5 & 21,4 & 10,2 & 461,3 & 250,3 \\
\hline 19 & $3-3 A$ & 322,6 & 96,7 & 0,721 & 4,5 & 20,3 & 8,0 & 458,2 & 246,9 \\
\hline 20 & $3-4 A$ & 370,9 & 97,0 & 0,721 & 4,5 & 20,8 & 9,9 & 461,2 & 250,3 \\
\hline Média & & 374,8 & 100,0 & 0,723 & 4,4 & 21,7 & 9,5 & 460,7 & 249,6 \\
\hline $\mathrm{CV}(\%)$ & & 10,4 & 4,5 & 0,354 & 5,7 & 8,5 & 10,8 & 0,4 & 0,7 \\
\hline 21 & $3-1 \mathrm{~B}$ & 377,4 & 109,7 & 0,721 & 4,5 & 20,8 & 10,9 & 465,2 & 255,0 \\
\hline 22 & $3-2 B$ & 424,8 & 127,1 & 0,718 & 4,5 & 20,8 & 9,0 & 468,1 & 259,2 \\
\hline 23 & $3-3 B$ & 362,6 & 112,4 & 0,718 & 4,2 & 21,6 & 9,6 & 465,9 & 256,8 \\
\hline 24 & $3-4 B$ & 488,2 & 125,8 & 0,716 & 4,6 & 20,2 & 9,9 & 471,2 & 260,2 \\
\hline Média & & 413,3 & 118,8 & 0,718 & 4,5 & 20,9 & 9,9 & 467,6 & 257,8 \\
\hline CV(\%) & & 13,7 & 7,6 & 0,307 & 3,9 & 2,8 & 8,1 & 0,6 & 0,9 \\
\hline 25 & $4-1 \mathrm{~A}$ & 260,1 & 69,8 & 0,718 & 5,0 & 18,2 & 9,8 & 456,1 & 247,3 \\
\hline 26 & $4-2 A$ & 265,3 & 70,2 & 0,718 & 7,0 & 12,7 & 10,5 & 458,5 & 249,9 \\
\hline 27 & $4-3 A$ & 273,2 & 70,9 & 0,721 & 6,8 & 12,6 & 9,2 & 455,6 & 245,2 \\
\hline 28 & $4-4 A$ & 317,4 & 72,7 & 0,718 & 5,0 & 18,2 & 10,0 & 462,0 & 252,9 \\
\hline Média & & 279,0 & 70,9 & 0,719 & 6,0 & 15,4 & 9,9 & 458,1 & 248,8 \\
\hline CV(\%) & & 9,4 & 1,8 & 0,195 & 18,5 & 20,8 & 5,4 & 0,6 & 1,3 \\
\hline 29 & $4-1 \mathrm{~B}$ & 347,3 & 49,0 & 0,718 & 5,6 & 16,7 & 10,2 & 463,2 & 251,2 \\
\hline 30 & $4-2 B$ & 357,7 & 56,1 & 0,721 & 7,2 & 11,7 & 10,7 & 460,2 & 250,8 \\
\hline 31 & $4-3 B$ & 334,0 & 43,7 & 0,716 & 6,5 & 13,1 & 9,2 & 463,8 & 251,1 \\
\hline 32 & $4-4 B$ & 322,7 & 44,0 & 0,713 & 6,8 & 12,6 & 9,7 & 462,1 & 248,2 \\
\hline Média & & 340,4 & 48,2 & 0,717 & 6,5 & 13,5 & 10,0 & 462,3 & 250,3 \\
\hline CV(\%) & & 4,5 & 12,0 & 0,483 & 10,4 & 16,2 & 6,5 & 0,3 & 0,6 \\
\hline 33 & $5-1 \mathrm{~A}$ & 471,9 & 99,6 & 0,724 & 5,1 & 17,4 & 8,9 & 473,7 & 254,5 \\
\hline 34 & $5-2 A$ & 480,6 & 91,8 & 0,718 & 5,8 & 15,2 & 10,4 & 475,0 & 256,2 \\
\hline 35 & $5-3 A$ & 467,0 & 87,8 & 0,721 & 6,0 & 14,8 & 12,1 & 475,1 & 255,6 \\
\hline 36 & $5-4 A$ & 412,1 & 73,8 & 0,724 & 5,8 & 15,2 & 10,6 & 473,5 & 253,4 \\
\hline Média & & 457,9 & 88,3 & 0,722 & 5,7 & 15,7 & 10,5 & 474,3 & 254,9 \\
\hline $\mathrm{CV}(\%)$ & & 6,8 & 12,2 & 0,355 & 7,0 & 7,6 & 12,5 & 0,2 & 0,5 \\
\hline 37 & $5-1 \mathrm{~B}$ & 551,1 & 85,4 & 0,721 & 6,0 & 14,8 & 12,3 & 479,2 & 257,7 \\
\hline 38 & $5-2 B$ & 492,9 & 77,5 & 0,724 & 5,8 & 14,9 & 11,7 & 480,9 & 258,5 \\
\hline 39 & $5-3 B$ & 583,4 & 101,7 & 0,721 & 5,8 & 15,4 & 10,8 & 481,7 & 262,9 \\
\hline 40 & $5-4 B$ & 520,2 & 78,5 & 0,724 & 6,1 & 14,5 & 12,2 & 478,5 & 257,4 \\
\hline Média & & 536,9 & 85,8 & 0,722 & 5,9 & 14,9 & 11,8 & 480,1 & 259,1 \\
\hline CV $(\%)$ & & 7,3 & 13,0 & 0,216 & 2,5 & 2,5 & 5,8 & 0,3 & 1,0 \\
\hline CV médio & 7. A (\%) & 7,7 & 6,8 & 0,288 & 10,9 & 15,5 & 7,3 & 0,5 & 1,2 \\
\hline CV médio & 7. B (\%) & 10,8 & 12,6 & 0,359 & 6,2 & 7,9 & 5,3 & 0,5 & 1,1 \\
\hline CV médio & l (\%) & 9,3 & 9,7 & 0,323 & 8,5 & 11,7 & 6,3 & 0,5 & 1,1 \\
\hline
\end{tabular}


BARBAR, L.C. e MELO, V.F. Variabilidade das características químicas...

heterogeneidade mineralógica dessa rocha sedimentar. O argilito da Formação Guabirotuba apresenta cor variegada, com manchas brancas, vermelhas e amarelas, em função da segregação das fases minerais na ocasião da formação da rocha. Tomando as amostras compostas 15 e 16 como exemplos (quadrantes separados por apenas $0,5 \mathrm{~m}$ - Figura 1), provavelmente, as variações nos teores dos minerais poderiam influenciar no desenvolvimento das plantas, uma vez que as raízes explorariam microambientes distintos a curtas distâncias horizontais. O teor de caulinita da amostra 14 é $43 \%$ superior ao teor do mineral na amostra 15 (Tabela 4). Quanto maior a quantidade de caulinita em relação aos óxidos de $\mathrm{Fe}$ (hematita e goethita) e Al (gibbsita) nos ambientes de clima tropical úmido (sistemas com predomínio de cargas dependentes de $\mathrm{pH}$ ), maior a CTC do solo, devido ao menor ponto de carga zero do primeiro mineral (BRIAN e SPOSITO, 1997; FONTES et al., 2001). A exposição de grupos silanol ( $\mathrm{Si}-\mathrm{O}$ ) nas bordas da superfície siloxana da caulinita permite a formação de cargas negativas mesmo em baixos valores de pH (TARI et al., 1999).

As características cristalográficas da caulinita obtidas por DRX e temperatura de desidroxilação (TD) da caulinita e gibbsita por análise termodiferencial são mostradas na Tabela 4. A TD da gibbsita variou de $245,2^{\circ} \mathrm{C}$ a $262,9^{\circ} \mathrm{C}$, com média de $254,1^{\circ} \mathrm{C}$ enquanto que, a caulinita sofreu desidroxilação à temperatura compreendida entre $455,6^{\circ} \mathrm{C}$ e $485,1^{\circ} \mathrm{C}$, com média de $470,4^{\circ} \mathrm{C}$. Existe uma relação direta entre TD e teores e grau de cristalinidade da caulinita (MELO et al., 2001b). As maiores espessuras da caulinita [maiores valores de DMC (001)] foram observadas nas amostras 1 a 8 , atribuídas a uma maior nucleação do mineral, favorecendo o aumento no tamanho das partículas. Os valores dos índices de cristalinidade de Hughes Brown (ICHB) (HUGHES e BROWN,
1979) foram relativamente baixos (Tabela 4), refletindo o elevado grau de desordem estrutural da caulinita (SINGH e GILKES, 1992). Aparentemente, têm-se maiores variações nos teores dos minerais do que em suas características cristalográficas, principalmente, para os atributos onde as estimativas por DRX $[\mathrm{d}(001)$ da caulinita] e por análise térmica (temperatura de desidroxilação da caulinita e gibbsita) são mais precisas (Tabela 4). A determinação do DMC no domínio (001) da caulinita tem aspecto subjetivo, pela dificuldade da medição da largura a meia altura da reflexão (001) nos difratogramas de raios- $X$. Os valores de $\mathrm{CV}$ para o Índice de Cristalinidade de Hughes e Brown (ICHB) foram consistentemente maiores no horizonte $A$ em relação ao horizonte $B$. No horizonte superficial do solo, diferenças locais nos compostos orgânicos podem interferir na cristalinidade da caulinita (MELO et al., 2001b).

\section{CONCLUSÕES}

1) Mesmo em estudos de atributos mais estáveis ou resistentes à mudança em função do tempo no solo, como a mineralogia das frações silte e argila, deve-se preferir a amostragem composta como forma de representar melhor a área.

2) Os valores dos coeficientes de variação (CV) entre as repetições tomadas a curtas distâncias horizontais foram inversamente proporcionais à estabilidade da característica do solo analisada: menores valores de CV para os teores totais de $\mathrm{Fe}_{2} \mathrm{O}_{3}$ e $\mathrm{Al}_{2} \mathrm{O}_{3}$ (CV entre 0,9 a $14,2 \%$ ) e teores de minerais de alta cristalinidade (caulinita e gibbsita) (CV entre 1,8 a 17,5\%); comportamento oposto foi verificado para os óxidos de $\mathrm{Fe}$ e Al de baixa cristalinidade (CV entre 6 a 109,7\%).

3) Verificaram-se maiores variações locais nos teores de caulinita e gibbsita do que nas características cristalográficas desses minerais.

\section{REFERÊNCIAS}

1. ANAND, R.R.; GILKES, R.J. Mineralogical and chemical properties of weathered magnetite grains from lateritic saprolite. Journal of Soil Science, v. 35, p. 559-567, 1984.

2. BARRETO, A.C.; NOVAIS, R.F.; BRAGA, J.M. Determinação estatística do número de amostras simples de solo por área para avaliação de sua fertilidade. Revista Ceres, v. 21. n. 2, p. 142-147, 1974.

3. BIGHAM, J.M.; GOLDEN, D.C.; BOWEN, L.H.; BUOL, S.W.; WEED, S.D. Iron oxide mineralogy of well-drained Ultisols and Oxisols: I. Characterization of iron oxides in soil clays by Mössbauer spectroscopy, X-ray diffractometry, and selected chemical techniques. Soil Science Society of America Journal, v. 42, n. 7. p. 816-825, 1978.

4. BRIAN, K.S.; SPOSITO, G. Surface charge properties of kaolinite. Clays Clay Minerals, v. 45, p. 85-91, 1997.

5. CATANS, R.A.; GALLO, J.R.; GARGANTINI, H. Amostragens de solo para estudos de fertilidade. Bragantia, v. 14, n. 1, p.14-26, 1954.

6. CURI, N.; FRANZMEIER, D.P. Toposequence of Oxisols from the central plateau of Brazil. Soil Science Society of America Journal, v. 48, n. 1. p. 341-346, 1984.

7. EMBRAPA. Empresa Brasileira de Pesquisa Agropecuária. Centro Nacional de Pesquisas de Solos. Sistema Brasileiro de classificação de solos. Brasília: Embrapa, Serviço de Produção de Informação, 1999. 412 p.

8. ESSINGTON, M.E. Soil and water chemistry. Boca Raton: CRC Press, 2004. 523 p.

9. FONTES, M.P.F.; WEED, S.B. Iron oxides in selected brazilian Oxisols. I. Mineralogy. Soil Science Society of America Journal, v. 55, p. 1143-1149, 1991.

10. FONTES, M.P.F.; CAMARGO, O.A.; SPOSITO, G. Eletroquímica das partículas coloidais e sua relação com a mineralogia de solos altamente intemperizados. Scientia Agricola, v. 58, p. 627-646, 2001.

11. GHIDIN, A.A.; MELO, V.F.; LIMA, V.C.; LIMA, J.M.J.C. Toposseqüências de Latossolos originados de rochas basálticas no Paraná. I - Mineralogia da fração argila. Revista Brasileira de Ciência do Solo, v. 30, n. 2, p. 293-306, 2006. 
12. GOLDICH, G.G. A study in rock weathering. Journal of Geology, v. 46, p. 17-58, 1938.

13. HUGHES, J.C.; BROWN, G.A cristallinity index for soil kaolinite and its relation to parent rock, climate and soil maturity. Journal of Soil Science, v. 30, n. 2, p. 557-553, 1979.

14. JACKSON, M.L.; LIM, C.H.; ZELAZNY, L.W. Oxides, hydroxides, and aluminosilicates. In: KLUTE, A. (Ed.). Methods of soil analysis. Part 1 - Physical and mineralogical methods. Madison: American Society of Agronomy, 1986. p.101-150.

15. JACKSON, M.L. Soil chemical analysis - advanced course. Madison: Prentice-Hall, 1979. 895 p.

16. KÄMPF, N.; RESENDE, M.; CURI, N. Iron oxides in brazilian soils. In: INTERNATIONAL SOIL CLASSIFICATION WORSHOP, 8, Curitiba. Anais. Curitiba: Empresa Brasileira de Pesquisa Agropecuária, Universidade Federal do Paraná, 1988. p. $71-77$.

17. KÄMPF, N.; CURI, N. Argilominerais em solos brasileiros. Tópicos em Ciência do Solo, v. 3, p. 1-54, 2003.

18. KITCHEN, N.R.; HAVLIN, J.L.; WESTFALL, D.G. Soil sampling under no-till banded phosphorus. Soil Science Society of America Journal, v. 54, n. 8, p. 1661-1665, 1990

19. KLUG, H.P.; ALEXANDER, L.E. X-ray diffraction procedures for polycrystalline and amorphous materials. New York: John Wiley, 1954. 716 p.

20. LIM, C.H., JACKSON, M.L. Dissolution for total elemental analysis. In: PAGE, A.L. (Ed.) Methods of soil analysis. Part 2 - Chemical and microbiological properties. Madison: American Society of Agronomy, 1986. p. 1-12.

21. McKEAGUE, J.A. Manual on soil sampling and methods of analysis. Otawa: Canadian Society of Soil Science, 1978. $212 \mathrm{p}$

22. MEHRA, O.P.; JACKSON, M.L. Iron oxide removal from soils and clays by a ditionite-citrate system buffered with sodiumbicarbonate. Clays and Clay Minerals, v. 7, n. 1, p. 317-327, 1960.

23. MELO, V.F.; FONTES, M.P.F.; NOVAIS, R.F.; SINGH, B.; SCHAEFER, C.E.G.R. Características dos óxidos de ferro e de alumínio de diferentes classes de solo. Revista Brasileira de Ciência do Solo, v. 25, n. 1, p. 9-32, 2001a.

24. MELO, V.F.; SINGH, B.; SCHAEFER, C.E.G.R.; NOVAIS, R.F.; FONTES, M.P.F.F. Chemical and mineralogical properties of kaolinite-rich Brazilian soils. Soil Science Society of America Journal, v. 65, n. 4, p 1324-1333, 2001b.

25. MELO, V.F.; SCHAEFER, C.E.G.R.; NOVAIS, R.F.; SINGH, B.; FONTES, M.P.F. Potassium and magnesium in clay minerals of some Brazilian soil as indicated by a sequential extraction procedure. Communication in Soil Science and Plant Analysis, v. 33, n. 13-14, p. 2203-2225, 2002.

26. MEYER, P.L. Probabilidade: aplicações à estatística. Rio de Janeiro: Livros Técnicos e Científicos, 1983. 426 p.

27. POPP, J.H. Geologia geral. Rio de Janeiro: Livros Técnicos e Científicos, 1987. 299 p.

28. SCHAEFER, C.E.G.R. Brazilian latosolos and their B horizon microstructure as long-term biotic constructs. Australian Journal of Soil Research, v. 39, p. 909-926, 2001.

29. SCHWERTMANN, U.; KÄMPF, N. Properties of goethite and hematite in kaolinitic soils of Southern and Central Brazil. Soil Science, v. 139, n. 2, p.344-350, 1985.

30. SCHWERTMANN, U.; TAYLOR, R.M. Iron oxides. In: DIXON, J.B.; WEED, S.B., (Eds.) Minerals in soil environments. 2. ed. Madison: Soil Science Society of America, 1989. p. 380-427.

31. SINGH, B.; GILKES, R.J. Properties of soil kaolinites from south-westen Australia. Journal of Soil Science, v. 43, n. 2, p.645-667, 1992.

32. SPIECEL, M.R. Probabilidade e estatística. São Paulo: Ceres, 1978. 528 p.

33. TARÌ, G.; BOBOS, I.; GOMES, C.S.F.; FERREIRA, J.M.F. Modification of surface charge properties during kaolinite to

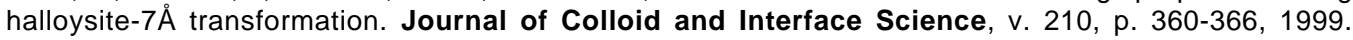

34. TOLEDO, F.H.R.B. Caracterização mineralógia e analise química dos agregados de duas classes de latossolos do estado do Paraná. Curitiba, 2006. 25 f. (Relatório de Iniciação Científica) - Curso de Agronomia, Setor de Ciências Agrárias, Universidade Federal do Paraná.

35. VIEIRA, L.S. Introdução à bioestatística. Rio de Janeiro: Editora Campus, 1980. 294 p.

36. WHITE, A.F.; BRANTLEY, S.L. Chemical weathering rates of silicate minerals: An overview. Reviews in Mineralogy, v. 31, p. 1-22, 1995.

37. WOLLLENHAUPT, N.C.; WOLKOWSKI, R.P.; CLAYTOPN, M.K. Mapping soil test phosphorus and potassium for variablerate fertilizer application. Journal of Production Agriculture, v. 7, n. 4, p. 441-448, 1994.

Recebido em 14/05/2007 Aceito em 03/03/2008 
